\title{
High-resolution numerical modeling of wave-supported gravity-driven mudflows
}

\author{
Tian-Jian Hsu, ${ }^{1}$ Celalettin E. Ozdemir, ${ }^{2}$ and Peter A. Traykovski ${ }^{3}$ \\ Received 7 July 2008; revised 30 October 2008; accepted 19 March 2009; published 14 May 2009.
}

[1] Wave-supported gravity-driven mudflow has been identified as a major offshore fine sediment transport mechanism of terrestrial sediment into the coastal ocean. This transport process essentially occurs within the wave boundary layer. In this study, wave-supported gravity-driven mudflow is investigated via a wave-phase-resolving high-resolution numerical model for fluid mud transport. The model results are verified with field observation of sediment concentration and near-bed flow velocities at Po prodelta. The characteristics of wave-supported gravity-driven mudflows are diagnosed by varying the bed erodibility, floc properties (fractal dimension), and rheological stresses in the numerical simulations. Model results for moderate concentration suggest that using an appropriately specified fractal dimension, the dynamics of wave-supported gravity-driven mudflow can be predicted without explicitly incorporating rheological stress. However, incorporating rheological stress makes the results less sensitive to prescribed fractal dimension. For high-concentration conditions, it is necessary to incorporate rheological stress in order to match observed intensity of downslope gravity-driven current. Model results are further analyzed to evaluate and calibrate simple parameterizations. Analysis suggests that when neglecting rheological stress, the drag coefficient decreases with increasing wave intensity and seems to follow a power law. However, when rheological stress is incorporated, the resulting drag coefficient is more or less constant (around 0.0013) for different wave intensities. Model results further suggest the bulk Richardson number has a magnitude smaller than 0.25 and is essentially determined by the amount of available soft mud (i.e., the erodibility), suggesting a supply limited condition for unconsolidated mud.

Citation: Hsu, T.-J., C. E. Ozdemir, and P. A. Traykovski (2009), High-resolution numerical modeling of wave-supported gravitydriven mudflows, J. Geophys. Res., 114, C05014, doi:10.1029/2008JC005006.

\section{Introduction}

[2] It is important to understand the fate of terrestrial sediment into the coastal ocean, because it determines for example the seabed properties and long-term coastal geomorphology [e.g., Wright and Coleman, 1972; Syvitski et al., 1988; Friedrichs and Wright, 2004]. The world's fluvial shelf system can be classified into several contrasting cases [e.g., Wright and Nittrouer, 1995]. However, for sediment transport we can generally consider the fluvial shelf system as either large rivers discharging into passive margins (or marginal seas) with relatively wide continental shelf, such as the Amazon shelf; or small mountainous rivers at tectonically active mountain belts that directly discharge into active margins [Milliman and Syvitski, 1992]. Since the

\footnotetext{
${ }^{1}$ Center for Applied Coastal Research, Civil and Environmental Engineering, University of Delaware, Newark, Deleware, USA.

${ }^{2}$ Civil and Coastal Engineering, University of Florida, Gainesville, Florida, USA.

${ }^{3}$ Applied Ocean Physics and Engineering, Woods Hole Oceanographic Institution, Woods Hole, Massachusetts, USA.
}

Copyright 2009 by the American Geophysical Union. 0148-0227/09/2008JC005006\$09.00 study of Milliman and Syvitski [1992], the significance of small mountainous river contributions to the world's total sediment discharge into the ocean has been emphasized.

[3] Terrestrial sediments delivered by moderate to large rivers are driven by seasonal variations. In contrast, for small mountainous river systems, major sedimentation events are dominated by large rainfall events that occur over a short period of time [Wheatcroft, 2000]. In the most extreme conditions, sediment delivery from small mountainous river mouths can generate episodic hyperpycnal plume because of their large sediment yield [Mulder and Syvitski, 1995; Wright and Nittrouer, 1995; Milliman et al., 2007]. In this case, hyperpycnal plume can carry large amount of fluvial sediment away from the shore in a relatively short period of time [Imran and Syvitski, 2000]. According to the analysis reported by Mulder and Syvitski [1995], except for several "dirty" mountainous rivers in the world where the hyperpycnal plume may be triggered by heavy rainfall due to typhoons or tropical cyclones on an annual basis [Milliman and Kao, 2005; Dadson et al., 2005], in most situations the initial deposition remains rather close to the river mouth. For example, at Eel River shelf of Northern California (USA) the probability 
of hyperpycnal plume occurrence is about once every 100 years. During the STRATAFORM field experiments at Eel River shelf [Nittrouer and Kravitz, 1996], the initial depositions from the river plume are observed to be at the inner shelf within the $40 \mathrm{~m}$ isobath [Geyer et al., 2000]. However, coring survey indicates that major flood deposits are found in the north of the river mouth in water depth of 50-100 m [Wheatcroft and Borgeld, 2000]. Such offshore transport of initially deposited terrestrial sediment must be caused by shelf resuspension processes. However, numerical modeling suggests that conventional resuspension mechanisms due to energetic waves and currents cannot account for the observed offshore transport [Harris et al., 2004]. Hence, other offshore transport mechanisms in additional to the conventional bottom boundary layer processes must be considered.

[4] According to the criterion suggested for the occurrence of turbidity current [Parker, 1982], the slope of Eel shelf (or most other continental shelves) is too mild to initiate autosuspending turbidity current for offshore sediment transport [Wright et al., 2001]. Therefore, such downslope gravity-driven transport has been associated with strong wave-current resuspension. During the STRATAFORM field experiment, direct measurements indicate that the concentration of the near-bed suspended sediment exceed the level of fluid mud $(\sim 10 \mathrm{~g} / \mathrm{L})$ [Ogston et al., 2000; Traykovski et al., 2000]. Hence, it is possible that such high sediment concentration may provide sufficient density anomaly to allow gravity-driven downslope mudflows. This conjecture is further confirmed by the measured near-bed flow velocity during fluid mud event that shows the maximum downslope current velocity occurs near the lutocline, consistent with typical gravity-current profile [Traykovski et al., 2000]. Hence, a conceptual picture can be described as follow. When there is sufficient amount of unconsolidated fine sediment deposits available near river mouth, they are resuspended by high bottom stress and boundary layer turbulence under energetic condition. The presence of a high-concentration sediment suspension further damps the carrier flow turbulence and can form a dense fluid mud layer near the bed [Trowbridge and Kineke, 1994], which may establish sufficient buoyancy anomaly to drive downslope gravitational transport. Apparently, the occurrences of wave-supported gravity-driven mudflows are also more frequent than previously believed. During the EuroSTRATAFORM program [Sherwood et al., 2004], wave-supported gravity-driven mudflow were also observed at Po River prodelta [Traykovski et al., 2007], which is a less energetic environment with a flatter slope than the Eel River shelf.

[5] Despite the critical role of downslope gravitational force, wave-supported gravity-driven mudflows are essentially a bottom boundary layer fluid mud process. In a typical coastal modeling system [e.g., Lesser et al., 2004; Harris et al., 2005; Warner et al., 2008], the numerical model is not designed to resolve near-bed wave boundary layer processes. In order to predict large-scale sediment transport and morphological evolution, wave-supported gravity-driven mudflows have to be parameterized as part of the bottom boundary layer module [e.g., Harris et al., 2004, 2005]. Several prior studies propose simplified nearbed formulations for gravity-driven fluid mud transport in the wave boundary layer [Wright et al., 2001; Harris et al., 2004; Fan et al., 2004] that can be coupled with coastal models. However, there are several critical assumptions in these formulations and empirical coefficients that need to be determined.

[6] Fluid mud resuspension processes in the wave-current bottom boundary layer can be predicted by detailed water column numerical model for fluid velocity and sediment concentration provided that appropriate turbulence closure and bottom boundary conditions are incorporated [Wiberg et al., 1994; van der Ham and Winterwerp, 2001; Hsu et al., 2007]. Using these small-scale models, it has been shown that with adequate supply of fine sediment that can be resuspended, the most important mechanism to predict the existence of fluid mud is the effect of sediment on damping the carrier flow turbulence. These numerical model results are consistent with earlier theoretical analysis and experimental evidence [Wolanski et al., 1988; Trowbridge and Kineke, 1994; Vinzon and Mehta, 1998]. Recently, Hsu et al. [2007] developed a numerical model for fine sediment transport. In this fine transport modeling framework, mechanisms such as rheological stresses, gravity-driven sediment flow and turbulence modulation by the presence of sediment are incorporated consistently in a formulation simplified from the multiphase flow theory by assuming small particle response time. They demonstrated that the new fine sediment transport model is able to predict the existence of fluid mud and subsequent downslope gravity-driven transport when driven by realistic cross-shelf and along-shelf nearbed wave-current velocities measured at Po River prodelta [Traykovski et al., 2007].

[7] Our current understanding on the dynamic of fluid mud processes in the wave boundary layer is limited. This is partially due to the difficulties in accurate measurement on turbulence, floc properties, rheology and erodibility in concentrated regime. Because the fluid mud model previously developed by Hsu et al. [2007] resolves the wave boundary layer, incorporates the damping of turbulence due to sediment in the $k-\varepsilon$ equations, and allows sediment concentration to drive gravitational flow in the momentum equations, the authors demonstrate that the model is able to predict observed wave-supported gravity-driven mudflows without explicitly incorporating more sophisticated cohesive sediment characteristics. However, without explicitly incorporating cohesive sediment characteristics, it is difficult to fully understand and quantify the fluid mud transport processes. The purpose of this study is twofold. First, the numerical model of Hsu et al. [2007] is revised to incorporate several well-known cohesive sediment characteristics in order to study their effects on wave-supported gravitydriven mudflows (section 3). Second, typical coastal modeling systems for morphodynamics cannot resolve processes occur within the wave boundary layer and hence these processes must be parameterized. Numerical model results are further analyzed (section 4) to evaluate the empirical parameters used in a 1-D depth-integrated parameterization of wave-supported gravity-driven mudflows suggested by Wright et al. [2001; see also Wright and Friedrichs, 2006].

[8] This paper is organized as follow. Model formulation is discussed in section 2. Specifically, we focus on several new revisions to the model that are unique for cohesive sediment. In section 3 , the capability of the numerical model 


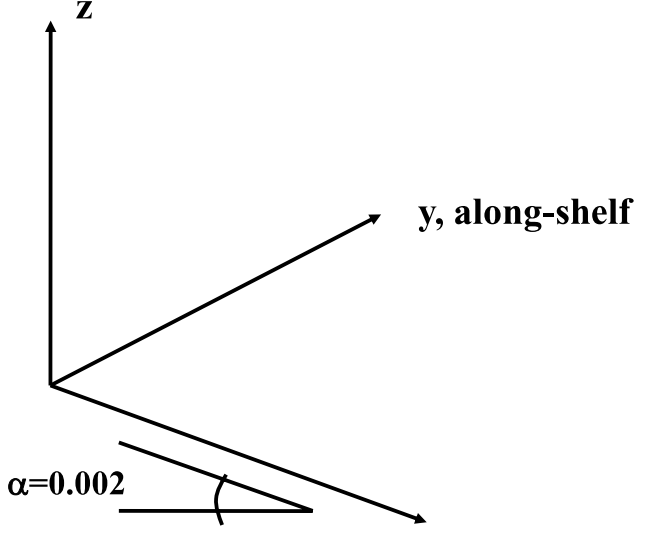

$x$, cross-shelf

Figure 1. Definition of coordinate system used in this study.

is demonstrated by comparing the model results with field data measured at Po prodelta when wave-supported gravity-driven mudflows are observed under two different conditions [Traykovski et al., 2007]. The nature and existence of wavesupported gravity-driven mudflows are further diagnosed by varying the floc properties, bed erodibility, rheological stresses and along-shelf current intensity. In section 4, we investigate the parameterization of wave-supported gravity-driven mudflow [e.g., Wright et al., 2001], specifically the dependence of drag coefficients and bulk Richardson numbers on the wave intensity. This study is concluded in section 5 .

\section{Numerical Model for Fluid Mud Transport}

\subsection{Model Formulation}

[9] A 1DV wave-phase-resolving fine sediment transport model [Hsu et al., 2007] is revised here to simulate wavesupported gravity-driven mudflows in consideration of the characteristics of cohesive sediment. The governing equation of the model is based on the Fast Equilibrium Eulerian approximation [Ferry and Balachandar, 2001] to the Eulerian two-phase equations. The characteristics of fluid-particle interaction can be quantified by the particle response time [e.g., Allen, 1985; Ferry and Balachandar, 2001]:

$$
T_{p}=\frac{\rho^{a} D^{2}}{18 \mu} f(\phi)
$$

where $\rho^{a}$ is the particle (floc) density, $D$ is the particle (floc) diameter, $\mu$ is the dynamic viscosity of the interstitial fluid, and $f(\phi)$ is a function representing hindered settling and is a function of the particle (floc) volume concentration $\varphi$. For the fine floc particles considered in this paper, we set $f(\phi)=$ $(1-\phi)^{4}$ [Richardson and Zaki, 1954]. Qualitatively, $T_{p}$ represents the timescale required to accelerate a particle (floc) from rest to the velocity of the carrier fluid flow and is proportional to $D^{2}$. Because the Fast Equilibrium Eulerian approximation requires that the particle response time to be small, the present model is appropriate for fine sediment (e.g., $D<\mathrm{O}(100) \mu \mathrm{m})$ transport in water.

[10] We consider fluid mud transport in the bottom wavecurrent boundary layer that is statistically homogeneous in the cross-shelf $x$ and along-shelf $y$ directions with a crossshore slope $\alpha$ (see Figure 1). The fluid mud is characterized by averaged floc (aggregate) diameter $D$ and floc density $\rho^{a}$ calculated by assuming the aggregates are of fractal structure [Kranenburg, 1994]:

$$
\rho^{a}=\rho+\left(\rho^{s}-\rho\right)\left(\frac{D}{D_{0}}\right)^{n_{f}-3}
$$

where $n_{f}$ is the fractal dimension, $\rho$ is the fluid density, and $\rho^{s}$ and $D_{0}$ are the primary particle density and diameter, respectively. The numerical model calculates Reynoldsaveraged cross-shelf velocity $u$, along-shelf velocity $v$ and the floc volume concentration $\varphi[H s u$ et al., 2007] in the bottom boundary layer. The governing equations for the Reynolds-averaged flow velocities are:

$$
\begin{gathered}
\frac{\partial u}{\partial t}=-\frac{1}{\rho} \frac{\partial p}{\partial x}+\frac{1}{\rho(1-\phi)}\left(\frac{\partial \tau_{x z}^{f}}{\partial z}+\frac{\partial \tau_{x z}^{s}}{\partial z}\right)+\frac{(s-1) \phi}{(1-\phi)} g \sin \alpha \\
\frac{\partial v}{\partial t}=-\frac{1}{\rho} \frac{\partial p}{\partial y}+\frac{1}{\rho(1-\phi)}\left(\frac{\partial \tau_{y z}^{f}}{\partial z}+\frac{\partial \tau_{y z}^{s}}{\partial z}\right)
\end{gathered}
$$

where $g=9.8 \mathrm{~m} / \mathrm{s}^{2}$ is the gravitational acceleration, $s=\rho^{a} / \rho$ is the specific gravity of the floc aggregate, $\tau_{x z}^{f}, \tau_{y z}^{f}$ are the fluid stresses, including viscous stress and turbulent Reynolds stress, and $\tau_{x z}^{s}, \tau_{y z}^{s}$ are sediment rheological stress due to interfloc interactions. Because of the boundary layer approximation, the pressure gradients $\partial p / \partial x$ in the crossshelf and $\partial p / \partial y$ in the along-shelf directions are iteratively determined from the prescribed wave-current velocity forcing. The Reynolds-averaged floc volume concentration $\varphi$ is calculated by

$$
\frac{\partial \phi}{\partial t}=\frac{\partial}{\partial z}\left(\phi T_{p}\left(1-s^{-1}\right) g+\frac{\nu_{t}}{\sigma_{\phi}} \frac{\partial \phi}{\partial z}\right)
$$

The first term on the right-hand side represents the settling and the second term represents turbulent suspension with the eddy viscosity $\nu_{t}$ calculated by a $k-\varepsilon$ closure and the Schmidt number $\sigma_{\varphi}$ is set to be 0.5 [Hsu et al., 2007]. In the original formulation derived by Hsu et al. [2007], there is an additional suspension term due to the vertical gradient of sediment normal stress $\tau_{z z}^{s}$. For cohesive sediment transport, sediment normal stress (often referred to as "effective stress") is considered important only in the concentrated aggregate network during consolidation or fluidization of the mud bed [see Winterwerp and van Kesteren, 2004, chap. 7]. In this study, we consider mobile suspensions of fluid mud above the concentrated aggregate network and hence the suspension mechanism due to sediment normal stress is neglected.

[11] Sediment mass concentration $c$ can be calculated from floc volume concentration as [Kranenburg, 1994]:

$$
c=\rho^{s} \phi\left(\frac{D}{D_{0}}\right)^{n_{f}-3}=\rho^{s} \phi\left(\frac{\rho^{a}-\rho}{\rho^{s}-\rho}\right)
$$

In this study, the primary particle density is given as $\rho^{s}=$ $2650 \mathrm{~kg} / \mathrm{m}^{3}$ and the primary particle diameter is set to be 
Table 1. Model Coefficients Adopted for $\mathrm{k}-\varepsilon$ Closure

\begin{tabular}{cc}
\hline Coefficient & Value \\
\hline$C_{\mu}$ & 0.09 \\
$C_{\varepsilon 1}$ & 1.44 \\
$C_{\varepsilon 2}$ & 1.92 \\
$\sigma_{k}$ & 1.0 \\
$\sigma_{\varepsilon}$ & 1.3 \\
$C_{\varepsilon 3}$ & 1.2 \\
$\sigma_{C}$ & 0.5 \\
\hline
\end{tabular}

$D_{0}=4 \mu \mathrm{m}$. In this paper, the floc diameter and fractal dimension are prescribed as constant. Hence, the dynamics of floc break up and aggregation in turbulent flow are not explicitly considered.

[12] The fluid shear stresses consist of viscous and turbulent Reynolds stresses. The turbulent Reynolds stresses are calculated by eddy viscosity and a $k-\varepsilon$ closure which is modified for suspended sediment transport:

$$
\tau_{x z}^{f}=\rho^{f}\left(\nu+\nu_{t}\right) \frac{\partial u}{\partial z}, \tau_{y z}^{f}=\rho^{f}\left(\nu+\nu_{t}\right) \frac{\partial v}{\partial z}
$$

with $\nu$ the fluid viscosity, and the eddy viscosity $\nu_{t}$ is calculated by turbulent kinetic energy $k$ and its dissipation rate $\varepsilon$ :

$$
\nu_{t}=C_{\mu} \frac{k^{2}}{\varepsilon}(1-\phi)
$$

The turbulent kinetic energy, $k$, and dissipation rate, $\varepsilon$, are estimated by their balance equations

$$
\begin{aligned}
(1-\phi) \frac{\partial k}{\partial t}= & \nu_{t}\left[\left(\frac{\partial u}{\partial z}\right)^{2}+\left(\frac{\partial v}{\partial z}\right)^{2}\right]+\frac{\partial}{\partial z}\left[\left(\nu+\frac{\nu_{t}}{\sigma_{k}}\right) \frac{\partial(1-\phi) k}{\partial z}\right] \\
& -(1-\phi) \varepsilon+(s-1) g \frac{\nu_{t}}{\sigma_{c}} \frac{\partial \phi}{\partial z}-\frac{2 \phi s k}{T_{p}+T_{L}}
\end{aligned}
$$

and

$$
\begin{aligned}
(1-\phi) \frac{\partial \varepsilon}{\partial t}= & C_{\varepsilon 1} \frac{\varepsilon}{k} \nu_{t}\left[\left(\frac{\partial u}{\partial z}\right)^{2}+\left(\frac{\partial v}{\partial z}\right)^{2}\right] \\
& +\frac{\partial}{\partial z}\left[\left(\nu+\frac{\nu_{t}}{\sigma_{\varepsilon}}\right) \frac{\partial(1-\phi) \varepsilon}{\partial z}\right]-C_{\varepsilon 2} \frac{\varepsilon^{2}}{k}(1-\phi) \\
& +C_{\varepsilon 3} \frac{\varepsilon}{k}\left[(s-1) g \frac{\nu_{t}}{\sigma_{c}} \frac{\partial \phi}{\partial z}-\frac{2 \phi s k}{T_{p}+T_{L}}\right] .
\end{aligned}
$$

Balance equations (9) and (10) herein have two additional terms compared to that of clear fluid. These terms represent the effects of fine sediment on carrier flow turbulence. Damping of turbulent kinetic energy due to sediment density stratification is accounted for in the fourth term of the right-hand side in equation (9). In addition, dissipation in carrier fluid turbulence caused by viscous drag of particles in the fluctuating field is included the last term of equation (9). This term is determined by using particle response time $T_{p}$, and turbulent eddy timescale $T_{L}$, which is calculated as:

$$
T_{L}=\frac{k}{6 \varepsilon}
$$

Numerical experiments suggest that in additional to density stratification, viscous drag can also cause significant damping of carrier flow turbulence especially in the concentrated regime near the bed in wave boundary layer. The numerical coefficients in equations (8)-(10) are specified by standard values for dilute flow [see $\mathrm{Hsu}$ et al., 2007, and reference therein]. These coefficients are shown in Table 1.

[13] To solve the model equations we also need closures on sediments stresses $\tau_{x z}^{s}, \tau_{y z}^{s}$. Our current understanding of the rheological behavior of mud is limited because it depends not only on sediment concentration and grain properties but also the stage of consolidation, floc structure, and biological processes. Hence, it is difficult to adopt a universal closure. In reality, in situ rheological tests (or laboratory tests on mud obtained in situ) are necessary to provide empirically based rheological relations. Because information on the rheological closure for the specific field data set that we shall consider in this paper is not available, the model results for moderate fluid mud concentration case (section 3.1) are first presented without the consideration of rheology. Then, the effects of rheology on the dynamics of wave-supported gravity driven mudflows is studied qualitatively using a Bingham plastic closure (see section 3.1.3).

[14] Bottom boundary conditions for flow velocities, turbulence quantities and sediment concentration are required to solve the proposed fluid mud model. In the present model, the bottom stress $\tau_{b}(t)$ at any give time is calculated from the model results of flow velocities at the first grid above the bed by assuming that logarithmic velocity profiles hold. The bottom stress is then used directly as a bottom boundary condition for flow velocities. A no-flux boundary condition for turbulent kinetic energy that is appropriate for a sediment-laden boundary layer is adopted. These bottom boundary condition implementations require a fine vertical grid resolution near the bed to resolve the mud-laden wave boundary layer (vertical grid resolution of $2.5 \mathrm{~mm}$ is used in this study). Complete descriptions on the bottom boundary conditions for flow velocities and turbulence quantities are detailed by $H s u$ et al. [2007] and are not repeated here. However, the erosion flux for cohesive sediment due to applied bottom stress is a rather complicated process and deserves more attention.

\subsection{Bottom Boundary Condition of Sediment}

[15] The continuous erosion/deposition formulation is used here for the cohesive sediment bottom boundary condition [e.g., Sanford and Halka, 1993]. The following simple parameterization for the erosion (upward) flux is adopted:

$$
E=\beta\left(\frac{\tau_{b}(t)}{\tau_{c}(M)}-1\right)
$$

where $\beta(\mathrm{m} / \mathrm{s})$ is an empirical erosion flux coefficient and $\tau_{b}$ $(t)$ is the bottom stress calculated at every time step. In this study, we consider Type 1 erosion [Sanford and Maa, 2001] for cohesive sediment in which the critical bottom stress $\tau_{c}$ $(M)$ is parameterized as a function of the amount of eroded mass $M$. In contrast, Type 2 erosion adopts a constant critical bottom stress, which is physically more appropriate for noncohesive sediments. For cohesive sediment, $\tau_{c}$ is 
mainly determined by the consolidation process and biological processes. For a mud bed that is experiencing consolidation, the critical bottom stress increases as more mud is eroded from the bed. In contrast, the biological processes can either strengthen or reduce the critical stress and are often difficult to quantify. Complete description of these parameters require in situ sampling and characterization. In this study, we focus on wave-supported gravity driven mudflows measured on the Po prodelta during the EuroSTRATAFORM field program [Traykovski et al., 2007]. In situ erodibility tests for $\tau_{c}(M)$ in a nearby location can be obtained from Stevens et al. [2007] (the N14 site). Their measured erodibility results are fitted here with a power law relation as:

$$
\tau_{c}(M)=\sigma M^{1 / 2}
$$

with $\sigma=0.67$. Using equation (13) for critical bottom stress, the erosion flux coefficient $\beta$ in equation (12) is further chosen so that the model calculated sediment mass concentration very near the bed matches that the measured values reported by Traykovski et al. [2007]. In section 3.1.1 we also investigate the effect of adopting Type 2 erosion (usually used for noncohesive sediment) on the model results for wave-supported gravity-driven mudflows.

\section{Model Results}

\subsection{Moderate Concentration (Cases 1a-1d)}

[16] Field data on wave-supported gravity-driven mudflows measured on the Po prodelta [Traykovski et al., 2007] as part of the EuroSTRATAFORM program [Sherwood et al., 2004] are examined here. As reported by Traykovski et al. [2007], during high-concentration fluid mud events, sediment concentration profiles are measured by multifrequency Acoustic Backscatter Sensor and flow velocities are measured at two vertical locations, $75 \mathrm{~cm}$ above bed (cmab) and $11 \mathrm{cmab}$ using Acoustic Doppler Velocimeters. During the EuroSTRATAFORM field campaign, in situ erodibility tests were carried out at various locations along the Italian coast of Adriatic Sea [Stevens et al., 2007], including one site (N14) that is close to the measurement site of wavesupported gravity-driven mudflows. The standard approach of prescribed pressure gradients in the cross-shelf and along-shelf directions is used to drive the wave-current boundary layer flows [Davies et al., 1988; Hsu et al., 2007]. Measured time-dependent wave velocity time series in the cross-shelf and along-shelf directions are used to drive the numerical model to obtain the oscillatory forcing. For mean current forcing, constant pressure gradients in the cross-shelf and along-shelf directions are further added to obtain required mean current velocities measured at $75 \mathrm{cmab}$. The cross-shore slope at the Po prodelta is rather mild and is set to be $\alpha=0.002$.

[17] For the moderate-concentration case (Case 1, see Table 2 for more details) shown in Figure 2, measured sediment mass concentration near the bed is about $60 \mathrm{~g} / \mathrm{L}$ (see dotted curve in Figure 2b), which is sufficiently high to be considered a fluid mud event. However, this concentration is lower than another extremely high concentration event (Case 2) that shall be studied in section 3.2. Case 1 studied here is thus categorized as moderate concentration.
The RMS wave velocity of Case 1 is $0.52 \mathrm{~m} / \mathrm{s}$ and the wave period is $9.2 \mathrm{~s}$. The mean current in both the crossshelf and along-shelf directions are relatively weak (see Figure 2a). A constant floc diameter of $24 \mu \mathrm{m}$ and floc density of $\rho^{a}=1440 \mathrm{~kg} / \mathrm{m}^{3}$ are specified, which gives a fractal dimension $\mathrm{n}_{\mathrm{f}}=2.26$. The resulting settling velocity based on Stokes law is $0.14 \mathrm{~mm} / \mathrm{s}$. Because of relatively low floc volume concentration $(\sim<15 \%)$, the hindered settling correction is not significant for the results presented here. Sediment rheological stresses are set to zero. The mud erosion flux is calculated using equation (12) with critical bottom stress calculated by equation (13) following erodibility data provided by Stevens et al. [2007]. The empirical erosion flux coefficient $\beta$ is set to be $3 \times 10^{-5} \mathrm{~m} / \mathrm{s}$. The parameters specified here are considered as the reference case for Case 1 (see Table 1, Case 1a).

[18] The numerical model predicts the time-averaged concentration profile and the location of lutocline that are very similar to measured data (Figure $2 b$ ). Both measured and model-predicted time-averaged cross-shelf velocities indicate the occurrence of downslope gravity-driven mudflow. The numerical model predicts the largest downslope gravitational velocity to be $8.4 \mathrm{~cm} / \mathrm{s}$ at about $7 \mathrm{cmab}$, which cannot be validated using the measured data. However, measured flow velocity at $11 \mathrm{cmab}$ agrees well with the predicted results and it is likely that the actual downslope gravitational flow is larger than previously expected on the basis of measured data around lutocline. Measured and predicted time-averaged along-shelf flow velocities also agree well and indicate no downslope gravity-driven flow (Figure 3e). According to the predicted cross-shelf sediment flux (Figure 3d), it is clear that significant offshore sediment transport occurs because of sediment-induced gravity flow. This offshore transport cannot be speculated simply on the basis of flow velocity measured at $75 \mathrm{cmab}$, which shows a small onshore directed current. Therefore, the dynamics of the wave-supported downslope gravity-flow must be fully understood using small-scale approaches and further parameterized in order to predict large-scale coastal sediment transport processes. The gradient Richardson number (Figure 2e) calculated on the basis of time-averaged velocity and concentration profiles is around $1-2$ within the wave boundary layer and increases dramatically to about 100 at the lutocline because of the high-concentration gradient. Away from the wave boundary layer, the Richardson number in the current boundary layer reduces to around 0.3. In summary, turbulence is significantly damped in the wave boundary layer because of the presence of sediment. This is consistent with most prior observations on the formation of wave-induced fluid mud [Traykovski et al., 2000].

\subsubsection{Effect of Bed Erodibility}

[19] The bed erodibility for cohesive sediment is a highly variable parameter that depends on the level of consolidation, sediment properties and biological activity, etc [e.g., Stevens et al., 2007]. The erodibility in the reference case (Case 1a) is prescribed empirically as variable critical bottom stress using in situ data reported by Stevens et al. [2007]. However, in most cases in situ erodibility information is not available. Therefore, it is useful to examine the sensitivity of the model results to the variation of the critical bottom stress. Figures $3 \mathrm{a}$ and $3 \mathrm{~b}$ presents the results for 

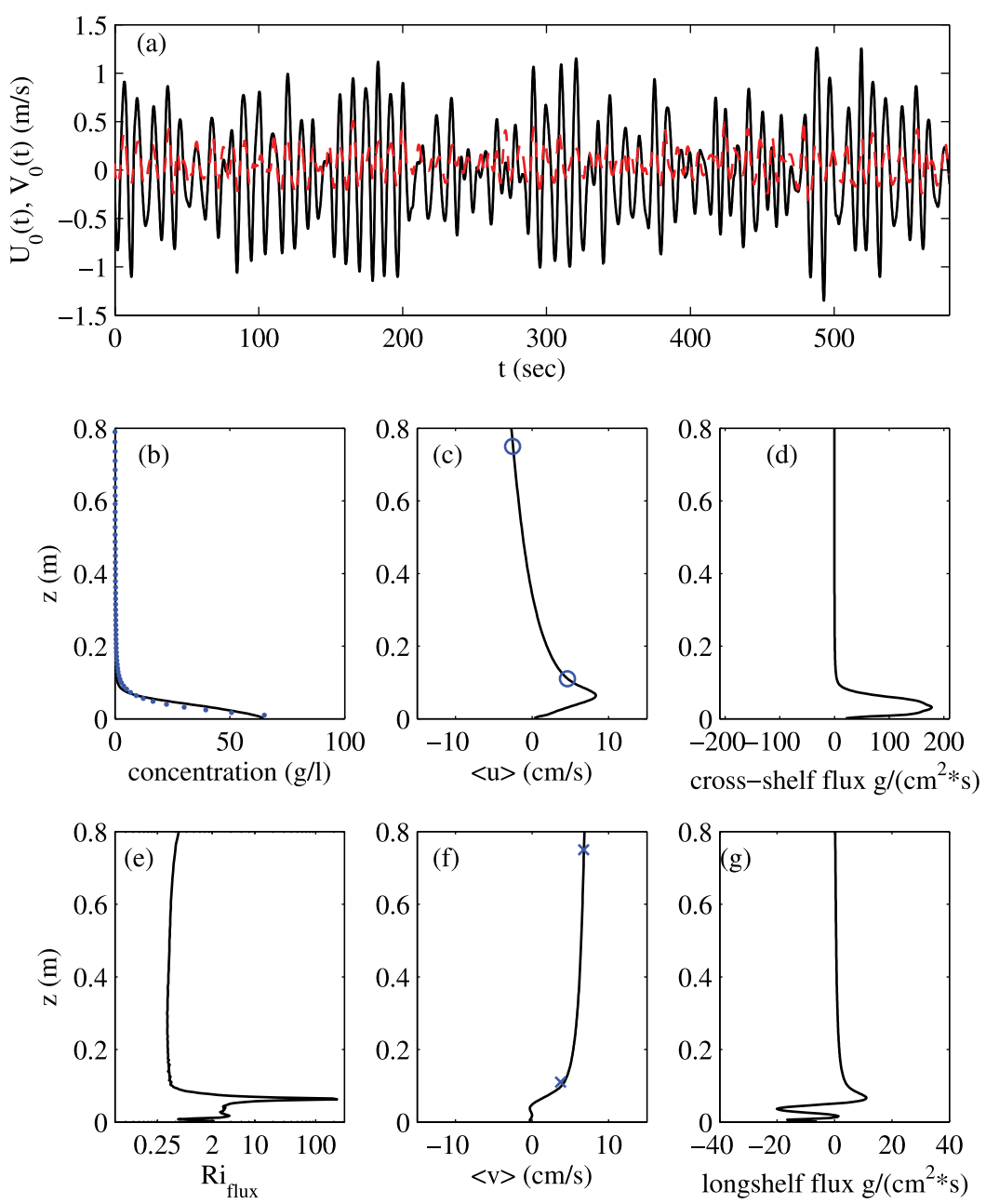

Figure 2. Model-data comparison of wave-supported gravity-driven mudflow at Po prodelta for moderate-concentration conditions (Case 1a). (a) Measured 520-s wave-current velocities time series in the cross-shelf (solid curve) and along-shelf (dashed curve) directions at 75 cmab [Traykovski et al., 2007] are used to drive the fluid mud model, (b) time-averaged mud concentration with the solid curve representing model results and dotted curve representing measured data, (c) modeled (solid curve) and measured (circles) time-averaged cross-shelf velocity profiles, (d) model results for cross-shelf sediment flux, (e) model results for gradient Richardson number based on time-averaged concentration and velocity profiles, (f) modeled (solid curve) and measured (crosses) time-averaged along-shelf velocity profile, and (g) model results for along-shelf sediment flux.

critical bottom stress and total eroded mass during the passage of the wave group for Case 1a. Because of the small settling velocity, the total suspended sediment mass does not respond to individual waves (compare Figure $3 \mathrm{~b}$ and Figure 2a). And in fact, the variation of total eroded mass and hence the critical bottom stress appears to evolve somewhat with the envelope of the wave group. But we can conclude that their overall changes in magnitude are rather

Table 2. Input Parameters for Numerical Model Tests Studied in This Paper

\begin{tabular}{|c|c|c|c|c|}
\hline & Case 1a & Case $1 \mathrm{~b}$ & Case $1 \mathrm{c}$ & Case $2 \mathrm{a}$ \\
\hline Comments & $\begin{array}{c}\text { Moderate } \\
\text { Concentration; } \\
\text { Reference Case }\end{array}$ & $\begin{array}{c}\text { Moderate } \\
\text { Concentration; } \\
\text { Test Erodibility }\end{array}$ & $\begin{array}{l}\text { Moderate } \\
\text { Concentration; } \\
\text { Test Rheology } \\
\text { and Fractal Dimension }\end{array}$ & $\begin{array}{c}\text { High } \\
\text { Concentration; } \\
\text { Reference Case }\end{array}$ \\
\hline Floc dynamics & Off & Off & Off & Off \\
\hline Floc density, $\rho^{\mathrm{a}}\left(\mathrm{kg} / \mathrm{m}^{3}\right)$ & 1440 & 1440 & 1280 & 1440 \\
\hline Floc diameter, $\mathrm{D}(\mu \mathrm{m})$ & 24 & 24 & 28 & 21 \\
\hline Fractal dimension & 2.26 & 2.26 & 2.09 & 2.23 \\
\hline Critical stress $(\mathrm{Pa})$ & $\begin{array}{l}\text { Limited erosion (13) } \\
\text { with } \sigma=0.67\end{array}$ & 1.12 Pa & $\begin{array}{l}\text { Limited erosion (13) } \\
\quad \text { with } \sigma=0.67\end{array}$ & $\begin{array}{c}\text { Limited erosion (13) } \\
\text { with } \sigma=0.36\end{array}$ \\
\hline $\begin{array}{l}\text { Erosion flux coeff. } \beta(\mathrm{m} / \mathrm{s}) \\
\text { Rheology }\end{array}$ & $\begin{array}{c}3 \times 10^{-5} \\
\text { Off }\end{array}$ & $\begin{array}{c}3 \times 10^{-5} \\
\text { Off }\end{array}$ & $\begin{array}{c}3 \times 10^{-5} \\
\text { On }\end{array}$ & $\begin{array}{c}3 \times 10^{-5} \\
\text { On }\end{array}$ \\
\hline
\end{tabular}



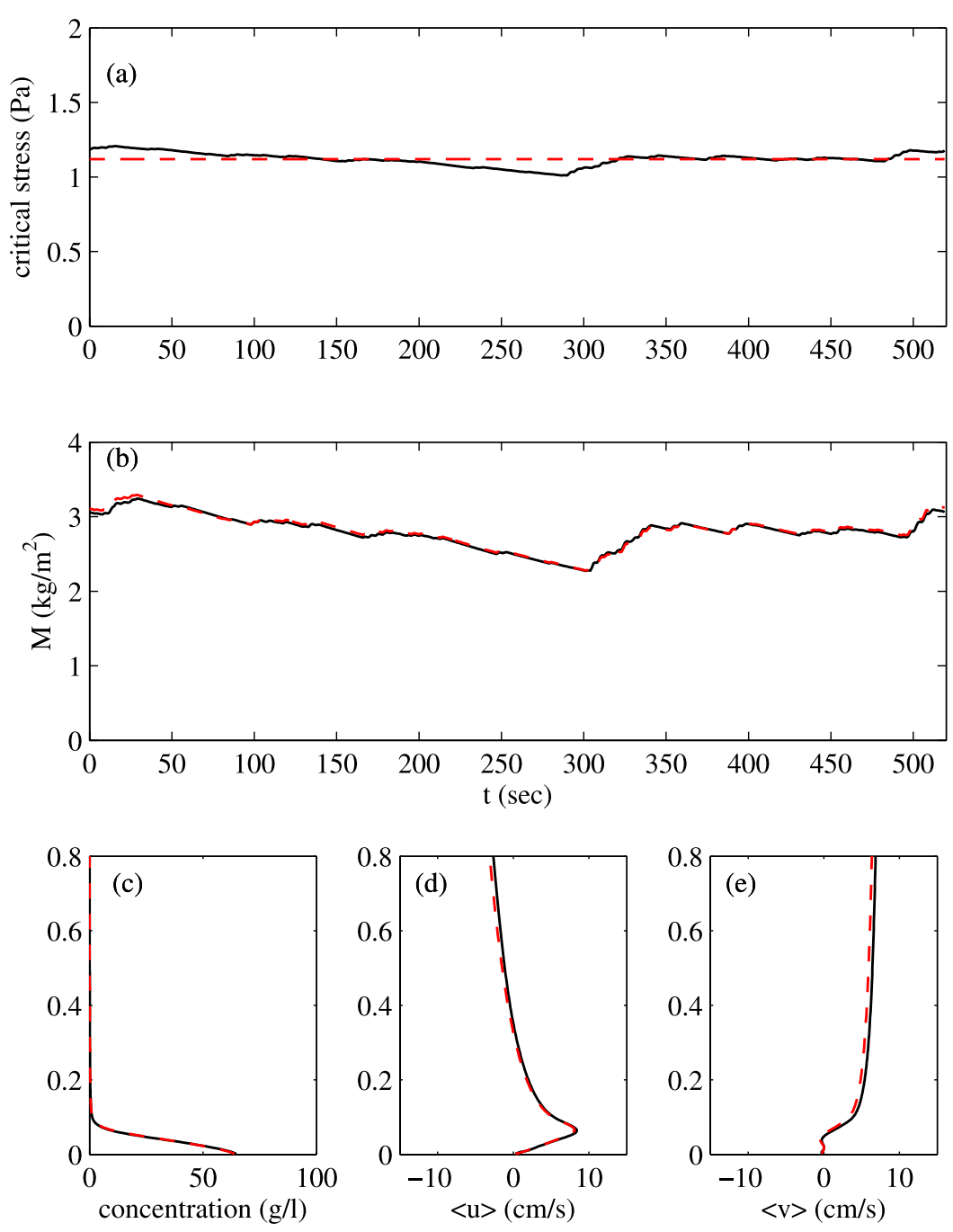

Figure 3. Model results using variable critical bottom stress based on in situ erodibility test (solid curves, Case 1a) and constant critical bottom stress (dashed curves, Case 1b). (a) Time series of calculated critical stress, (b) cumulative eroded mass, (c) time-averaged concentration profile, (d) crossshelf velocity profile, and (e) along-shelf velocity profile.

small. Using a constant critical bottom stress of $1.12 \mathrm{~Pa}$ which is equal to the averaged value of time-dependent critical stress due to the passage of the wave group (see Case $1 \mathrm{~b}$ in Table 1), the resulting time-averaged concentration and cross-shelf downslope velocity profile, and alongshelf velocity profiles (see Figures $3 \mathrm{c}, 3 \mathrm{~d}$, and $3 \mathrm{e}$, dashed curves) are very close to that using variable critical bottom stress. Therefore, we hypothesize that the details of intrawave variations of erodibility are not sensitive to the dynamics of wave-supported downslope gravity-driven mudflows, since the variations in wave forcing have a much smaller timescale than the settling timescale of the sediment in the wave boundary layer. This is different from the tidally dominated cohesive sediment transport processes in estuaries. However, it is emphasized here that information on the averaged magnitude of critical bottom stress is still required in order to obtain reasonable amount of available cohesive sediment. For practical implementation, in situ erodibility tests remain necessary unless the dynamics of seabed properties, including biological effects, can be explicitly modeled.

\subsubsection{Effect of Fractal Dimension}

[20] Cohesive sediment is transported as flocs. A single floc consists of loose aggregation of many fine primary particles. Floc properties and the dynamics of floc break up and aggregation process in turbulent boundary layer are among one of the least known processes in the present modeling effort. The fractal theory is a widely accepted model for quantifying the floc structure [Kranenburg, 1994]. Given the fractal dimension, the floc density can be calculated by equation (2) and sediment settling velocity can be further calculated. In the present formulation, the floc volume concentration is used as primary variable to calculate cohesive sediment transport and the mass concentration is further calculated by equation (6) using a prescribed fractal dimension. Therefore, it is critical to exam the effect of fractal dimension on wave-supported gravity-driven mudflows.

[21] According to field observation, the fractal dimension for estuarine mud is about 1.8 2.5 [Dyer and Manning, 1999; Winterwerp, 1998]. Numerical experiments for 

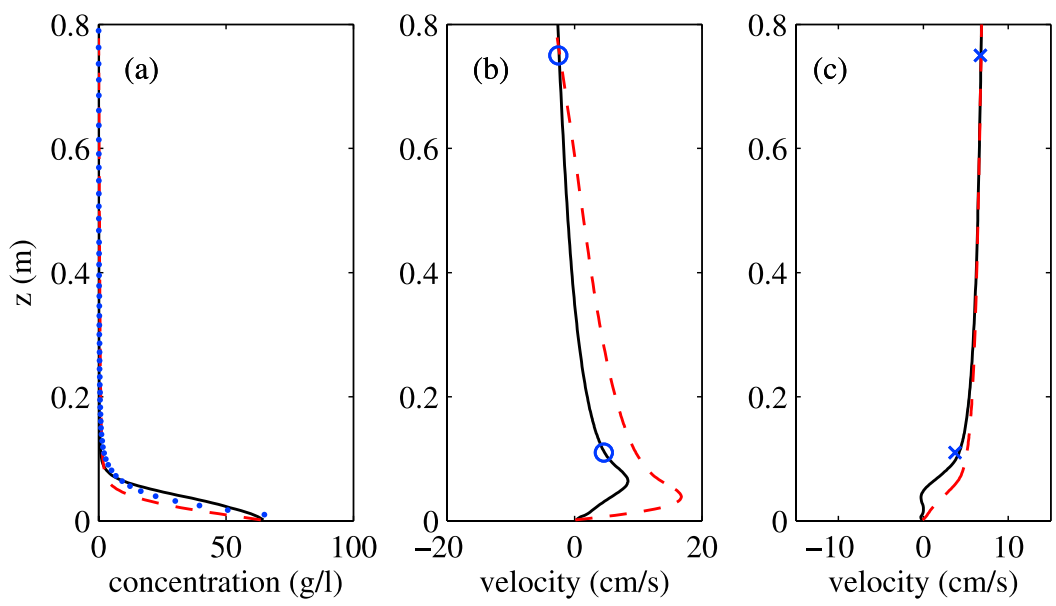

Figure 4. Model results using fractal dimension 2.26 (Case 1a, solid curves) and fractal dimension 2.09 (dashed curves). (a) Time-averaged mass concentration, (b) time-averaged cross-shelf velocity, and (c) time-averaged along-shelf velocity. Symbols are measured data.

Case 1a suggest that when rheological stress is neglected, the resulting downslope gravity-driven flow is sensitive to prescribed fractal dimension. The results shown in Figure 2 using fractal dimension $n_{f}=2.26$ can be considered as the optimum value to match with the measured data. A prescribed fractal dimension of 2.09 (2.2) gives maximum downslope velocity of about $16.8(11.5) \mathrm{cm} / \mathrm{s}$, which is about $100 \%(30 \%)$ larger than that of using a fractal dimension 2.26 (see Figure $4 \mathrm{~b}$ for results for $n_{f}=2.09$; results for $n_{f}=2.2$ are not shown). Similar features are also observed for the along-shelf current (Figure 4c). When fractal dimension is smaller, higher floc volume concentration is needed to achieve required sediment mass concentration (see equation (6)). Higher floc volume concentration also causes stronger damping of carrier flow turbulence via viscous drag (the last term in equations (9) and (10)) and stronger downslope mean current due to drag reduction [e.g., Gust, 1976]. According to the calculated time-averaged concentration profile (Figure 4a), the location of lutocline becomes lower when smaller fractal dimension is used. This also provides evidence that the carrier flow turbulence is damped more significantly when smaller fractal dimension is used.

[22] In summary, if the rheological stress is neglected, the model results are sensitive to fractal dimension and it can be used to fit the modeled to concentration and current velocities to measurements. In practice, measured data is not always available and it is important to develop some predictability of wave-supported gravity-driven mudflows. It is somewhat unsatisfying that model results for the magnitude of gravity currents are sensitive to the value of the fractal dimension. In section 3.1.3 it will be shown that rheological stresses cause a counteracting effect compared to drag reduction. Because rheological stress is proportional to floc volume concentration (see equation (15)), larger floc volume concentration causes stronger energy dissipation (friction) and smaller downslope mean current. Hence, model results calculated with rheological stress incorporated are less sensitive to the prescribed value of fractal dimension (see section 3.1.3 and Figure 5).
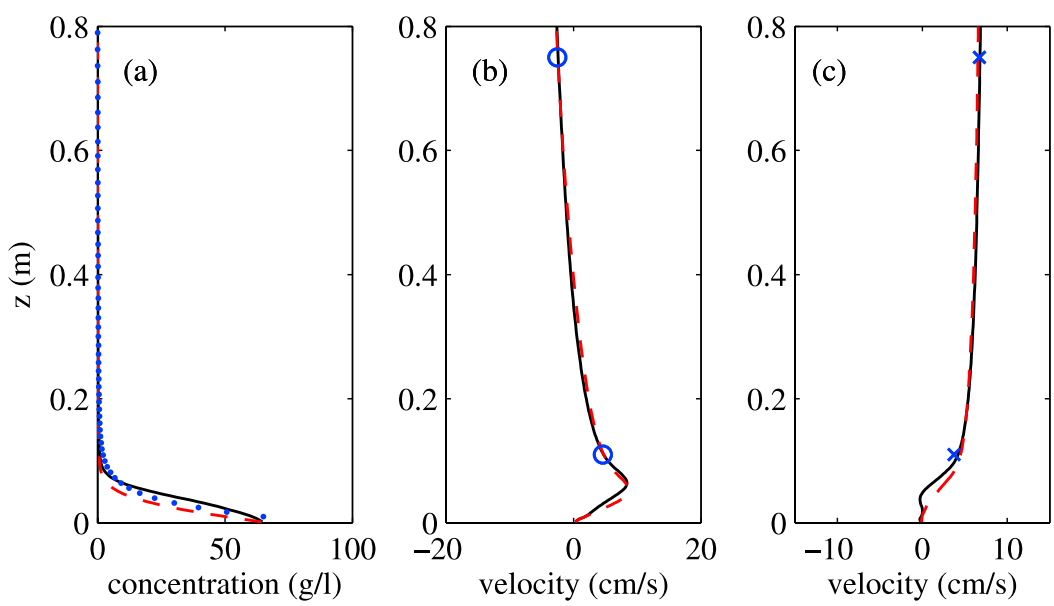

Figure 5. Model results for incorporating rheological stress but using two different values of fractal dimensions 2.26 (solid curves) and 2.09 (dashed curves, Case 1c). (a) Time-averaged sediment mass concentration profile, (b) cross-shelf velocity profile, and (c) along-shelf velocity profile. 


\subsubsection{Effect of Mud Rheology}

[23] When fluid mud concentration becomes sufficiently large such that the collisions among aggregates become rather frequent or the concentrated mud flocs form loosely packed aggregate network structure, rheological stresses need to be considered. For noncohesive particles, it is possible to propose more physical-based general closures for rheological stress [e.g., Nott and Brady, 1994]. However, because of complicated evolution of aggregate structure during interfloc interactions and biological effects of cohesive sediment, a universal formulation to represent the rheological behavior of fluid mud does not exist. For example, Dalrymple and Liu [1978] model such concentrated region as highly viscous fluid. Visco-elastic formulations are suggested by, Maa and Mehta [1987]. A more widely used rheological closure for various applications of industrial or environmental flows is the Bingham plastic formulation [e.g., Mei and Liu, 1987; Huang and Garcia, 1999]. Even when a specific rheological closure is chosen, empirical coefficients need to be prescribed on the basis of measured data. Because in situ rheological characterization is not available during the EuroSTRATAFORM field campaign, the main purpose of this section is to utilize a commonly used rheological closure and to study the effects of rheology on the behavior of wave-supported gravitydriven mudflow through numerical experiments.

[24] We adopt a rheological stresses closure for sediment shear stresses $\tau_{x z}^{s}, \tau_{y z}^{s}$ on the basis of a mathematical form that is similar to Bingham rheology previously used by $L e$ Hir et al. [2001] for modeling estuarine mud:

$$
\tau_{x z}^{s}=\rho^{f} \nu_{s} \frac{\partial u}{\partial z}, \tau_{y z}^{s}=\rho^{f} \nu_{s} \frac{\partial v}{\partial z}
$$

where the effective viscosity is calculated as

$$
\nu_{s}=\nu_{s 0} \phi^{k_{a}}\left[1+\frac{\gamma_{0}}{k_{b} \gamma_{0}+|\partial u / \partial z|}\right]
$$

Here, we specify the numerical coefficients as [Le Hir et al., 2001]:

$$
\nu_{s 0}=0.003\left(\mathrm{~m}^{2} / \mathrm{s}\right), k_{a}=3.0, k_{b}=0.001, \gamma_{0}=1.0(1 / \mathrm{sec})
$$

Notice that $\gamma_{0}$ is shown in equation (15) to balance the dimension and in fact is not an empirical parameter. The other three empirical parameters shown in (16) control the intensity of rheological viscosity and yield stress. The yield stress is controlled by $k_{b}$. The effective viscosity increases with mud concentration via a power law function with a prescribed $k_{a}$. The reference value of effective viscosity is specified by $\nu_{s} 0$, which is used here as a primary calibration parameter to match with the measured mean current velocity.

[25] The effects of rheological shear stress on wavesupported gravity-driven mudflow can be qualitatively evaluated by incorporating rheology closure (equations (14)(16)) in Case 1a (Figure 5, solid curves, fractal dimension $n_{f}=2.26$ ). Using $\nu_{s 0}=0.003 \mathrm{~m}^{2} / \mathrm{s}$, the resulting concentration profile is almost identical to that without incorporating rheology (compare the solid curves in Figure 5a and Figure $4 \mathrm{a}$ ), because the calculated near-bed floc volume concentration for Case 1a too small (about 10\%) to observe the effect of rheological stress. The maximum downslope gravity-driven current velocity calculated when rheology is incorporated reduces slightly to $7.8 \mathrm{~cm} / \mathrm{s}$ (compares to $8.4 \mathrm{~cm} / \mathrm{s}$ when rheology is not incorporated). The more important feature is that when the same rheological closure coefficients are used to calculate wave-supported gravitydriven mudflows with a smaller fractal dimension of $n_{f}=$ 2.09 , the resulting maximum downslope gravity-driven current velocity is reduced to $8.6 \mathrm{~cm} / \mathrm{s}$ (dashed curve in Figure $5 \mathrm{~b}$; this case is called Case $1 \mathrm{c}$ in Table 1). In other words, because of high near-bed floc concentration calculated with $n_{f}=2.09$ (about 20\%), the rheological closure significantly reduces the resulting downslope velocity from $16.8 \mathrm{~cm} / \mathrm{s}$ to $8.6 \mathrm{~cm} / \mathrm{s}$. Hence, when a rheological closure is adopted, the model results are much less sensitive to the variation of fractal dimension (compare dashed curves and solid curves in Figure 5 and Figure 4, respectively).

[26] When rheological stresses are not considered, flow energy is only dissipated by viscous and turbulent Reynolds stresses. And we have demonstrated in Figure 4 that because of damping of carrier flow turbulence and drag reduction, the turbulence Reynolds stresses and the resulting mean flow are sensitive to the value of fractal dimension. In contrast, when rheological shear stress is incorporated, a major portion of the energy dissipation is due to rheological stress when floc concentration is large. Because the magnitude of rheological stress increases with floc volume concentration, while the magnitude of Reynolds stress decrease with floc volume concentration. Consequently, the model results are less sensitive to prescribed fractal dimension when rheological stress is incorporated.

[27] In terms of improving our predictability on wavesupported gravity-driven mudflow with moderate concentration, our results based on numerical experiments give somewhat mixed message. It appears that if the floc is of larger fractal dimension, the rheological stress becomes negligible. However, when accurate information on fractal dimension is not known, the magnitude of rheological stress (i.e., the empirical coefficients in the rheological closure) can eventually become the determining factor to control the dynamics of mudflow. We conclude that the both the fractal dimension and rheological stress are critical information to model detailed fluid mud transport. Accurate information on fractal dimension is directly related to a quantitative description on rheological stresses. Certainly, more observational data on floc properties and rheology during fluid mud transport events are necessary to improve our predictability on wave-supported gravity-driven mudflows.

\subsubsection{Effect of Strong Along-Shelf Current}

[28] Recently, Ma et al. [2008] report evidence of downslope sediment-driven gravity flow that is mainly suspended by high along-shelf current (RMS wave velocity is only about $0.3 \mathrm{~m} / \mathrm{s}$ but the along-shelf current is as large as $0.35 \mathrm{~m} / \mathrm{s}$ at $42 \mathrm{cmab}$ ) near the mouth of Waiapu River, New Zealand. In terms of the dominant forcing responsible for keeping sediment suspended, such current-supported gravity flow is different from that observed at the mouth of Eel River or Po River. Most of the fluid mud events with sufficiently high concentration measured at Po during EuroSTRATAFORM are coincide with relatively low along-shelf current and strong RMS wave velocities. According to Ma et al. 

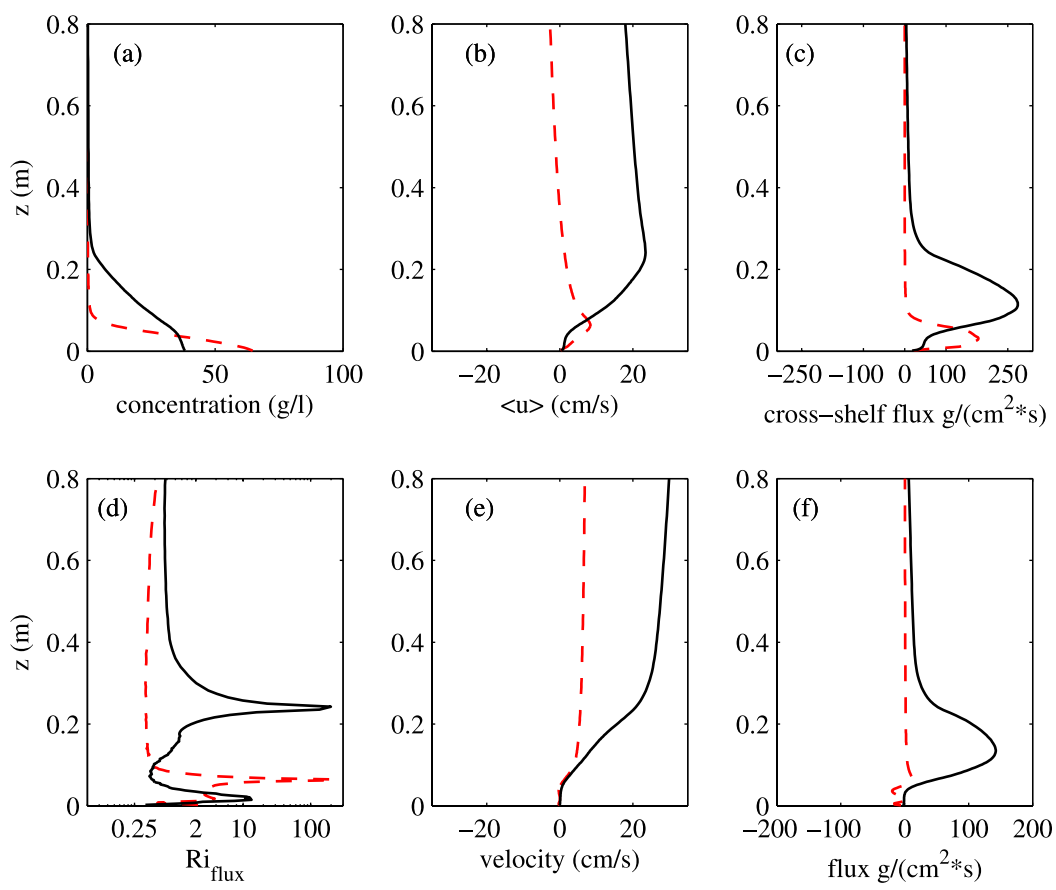

Figure 6. Model results for wave-supported gravity-driven mudflows when strong along-shelf current is applied to Case 1a (solid curves). Dashed curves represent results of Case 1a shown here for the purpose of comparison. (a) Time-averaged mud concentration, (b) time-averaged cross-shelf velocity profile, (c) cross-shelf sediment flux, model results for gradient Richardson number based on (d) timeaveraged concentration and (e) velocity profiles, (f) time-averaged along-shelf velocity profile, and (g) along-shelf sediment flux.

[2008], there are some characteristics of current-supported gravity-driven sediment flow that are distinct from wavesupported ones. In current-supported condition, sediment is not confined in the wave boundary layer because of strong current-induced mixing and the magnitude of the resulting downslope gravity flow is also larger.

[29] The fluid mud model developed in this study is based on a general wave-current bottom boundary layer formulation. Hence, the present model is utilized here to study the effect of strong along-shelf current on wave-supported gravity-driven mudflows by specifying a larger along-shelf pressure gradient in Case 1a. As shown in Figure 6e, larger along-shelf pressure gradient causes stronger along-shelf current of $30 \mathrm{~cm} / \mathrm{s}$ at $80 \mathrm{cmab}$ (solid curve), which is about 4.5 times larger than that of Case 1a (dashed curve). Sediment is mixing is increased in the water column. Hence, the lutocline is located at around $25 \mathrm{cmab}$, which is about 2 3 times higher than that of Case 1a (see Figure 6a). Moreover, the resulting downslope gravity-driven flow exceeds $20 \mathrm{~cm} / \mathrm{s}$ (Figure 6b) and significant offshore and along-shelf sediment transports are predicted (Figures $6 \mathrm{c}$ and 6f). These features are qualitatively consistent with field observed features of current-supported gravity-driven flow at the mouth of Waiapu River, New Zealand [Ma et al., 2008]. More detailed model-data comparison and numerical modeling study are necessary in order to better understand the mechanisms and the parameterization of currentsupported gravity-driven sediment flow.

\subsection{High Concentration (Case 2)}

[30] The near-bed fluid mud mass concentration observed in Case 2 exceeds $150 \mathrm{~g} / \mathrm{L}$ (Figure 7a), which is more than two times larger than the moderate-concentration case (Case 1 in section 3.1). However, measured RMS wave velocity and wave period are $0.51 \mathrm{~m} / \mathrm{s}$ and $8.9 \mathrm{~s}$, respectively, which are similar to that of Case 1 . Hence, it is likely that Case 2 is observed when more soft mud is available and the erodibility is larger to attain the observed high concentration under similar wave intensity. According to Traykovski et al. [2007], Case 2 was measured at the beginning of a wave event right after high-river discharge event [Traykovski et al., 2007, Figure 11, day 6.1]. In contrast, Case 1 is measured about $4 \mathrm{~h}$ later after $50 \%$ to $70 \%$ [see also Traykovski et al., 2007, Figure 11] of the available sediment had already been transported offshore by the downslope gravity flows. Using a similar floc diameter and fractal dimension that are used in Case 1a $\left(\rho^{a}=1440 \mathrm{~kg} / \mathrm{m}^{3}\right.$ and $\left.\mathrm{D}=21 \mu \mathrm{m}, \mathrm{n}_{\mathrm{f}}=2.23\right)$, the critical bottom stress (see equation (13)) suggested by Stevens et al. [2007] is too large to achieve measured magnitude of mud mass concentration. To simulate more unconsolidated soft mud during this high-concentration event, the critical bottom stress is reduced by setting $\sigma=0.36$ in equation (13). Model results further indicate that if rheology is not considered, the calculated downslope gravity-driven flow velocity is several times larger than the observed data. As explained in sections 3.1.2 and 3.1.3, the calculated large downslope current velocity is due to drag reduction phenomenon caused by damped turbulence via sediment density stratification. Under such high mud concentration the rheological stress is expected to be large. When Bingham rheology shown in equations (14)-(16) is incorporated (with $\nu_{s 0}$ increased to $0.03 \mathrm{~m}^{2} / \mathrm{s}$ ), the predicted downslope 

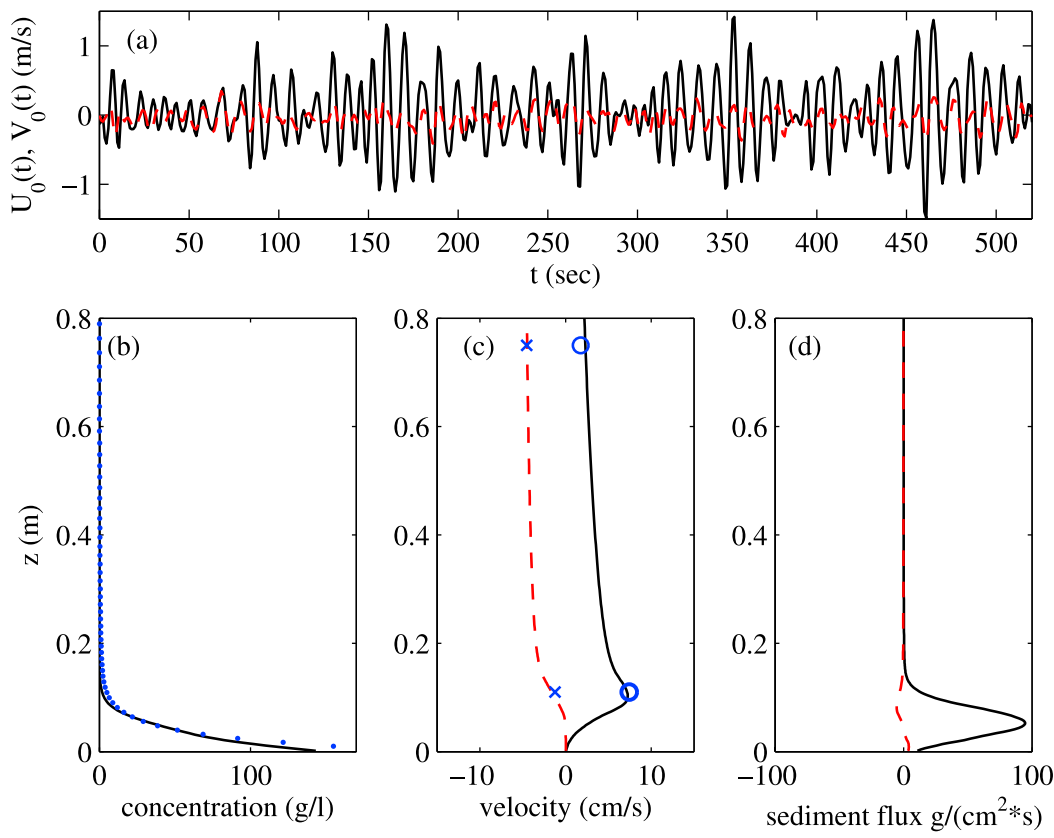

Figure 7. Model-data comparison of wave-supported gravity-driven mudflows for the highconcentration fluid mud event (Case 2). (a) Measured 520-s wave-current velocities time series in the cross-shelf (solid curve) and along-shelf (dashed curve) directions at $75 \mathrm{cmab}$ [Traykovski et al., 2007] is used to drive the fluid mud model, (b) time-averaged mud concentration with solid curve representing model results and dashed curve representing measured data, (c) modeled (solid curve) and measured (circles) time-averaged cross-shelf velocity profiles and along-shelf velocity profiles (dashed, model results, and crosses, measured data), and (d) modeled cross-shelf (solid) and along-shelf (dashed) sediment fluxes.

gravity-driven velocity is similar to the observed data (Figure 7c). In this case, the magnitude of $\nu_{s 0}$ is determined to fit the modeled current velocities to the measurements. However, it is emphasized here that the rheological stress must be incorporated for high-concentration conditions in order to obtain reasonable results.

[31] It is worth mentioning that one can use the identical erodibility formulation to that of Case 1 (i.e., $\sigma=0.67$ ) to obtain model results that are similar to measured data if the floc properties are set to be $\rho^{a}=1850 \mathrm{~kg} / \mathrm{m}^{3}$ and $D=16 \mu \mathrm{m}$ (results not shown). However, this corresponds to a rather large fractal dimension of $n_{f}=2.53$. Therefore, we decide to carry out the model study for this high-concentration case using reduced critical bottom stress as shown in Figure 7.

[32] In summary, model results suggest that similar magnitude of mud concentration and downslope gravity-driven mudflows may be predicted using several different combinations of erodibility, floc properties and magnitudes of rheology. In order to further understand the detailed dynamics of wave-supported gravity-driven mudflows, concurrent measurements on at least some of these properties are necessary.

\section{Parameterization}

\subsection{One-Dimensional Formulation}

[33] There are several simplified formulations for wavesupported gravity-driven mudflows ranging from simple algebraic formulations [Wright et al., 2001; Scully et al., 2002], to depth-integrated 1D mass balance formulation [Traykovski et al., 2000, 2007], and to more sophisticated wave-boundary layer module that require many flow and sediment parameters [Harris et al., 2004].

[34] The simplest and most commonly used parameterization for wave-supported gravity-driven mudflow is reviewed by Wright and Friedrichs [2006]. The wavesupported gravity-driven mudflow is parameterized as a momentum balance in the cross-shelf $(\mathrm{x})$ direction:

$$
B \sin \alpha=C_{D}|U| u_{g}
$$

with $u_{g}$ the gravity flow velocity, $C_{D}$ the drag coefficient, and $\sin \alpha$ the shelf slope. In the original formulation of Wright et al. [2001], the floc structure is not explicitly considered. For nonflocculated sediment, the buoyancy anomaly, $B$, is defined as

$$
B=g\left(s_{0}-1\right) \int_{0}^{h} \phi_{0} d z
$$

with $\phi_{0}=c / \rho^{s}$ is the solid volume concentration, $s_{0}$ is the specific gravity of the primary particle and $h$ the flow depth. For flocculated sediment, equation (6) is utilized and substituted into equation (18). Hence, the buoyancy anomaly can be calculated using floc volume concentration $\varphi$ and specific gravity of the floc $s$ as:

$$
B=g(s-1) \int_{0}^{h} \phi d z .
$$



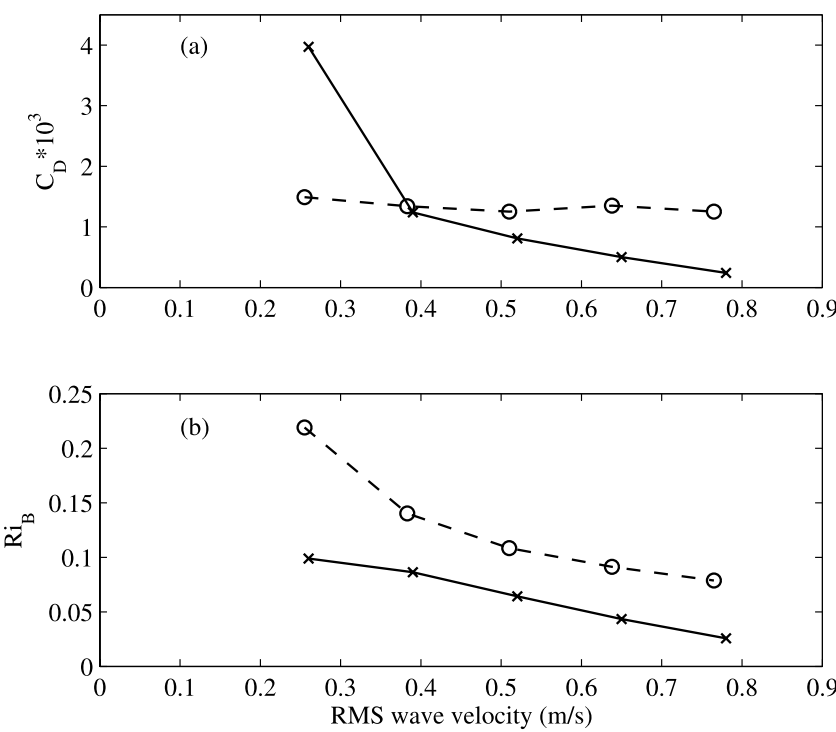

Figure 8. (a) Drag coefficients $\left(C_{D}\right)$ versus RMS wave velocity and (b) bulk Richardson number versus RMS wave velocity for moderate-concentration conditions (crosses) and high-concentration conditions (circles). Detailed numeric values are presented in Tables 3 and 4 .

The total velocity in equation (17) is defined as

$$
|U|=\sqrt{u_{w}^{2}+v_{w}^{2}+u_{c}^{2}+v_{c}^{2}+u_{g}^{2}}
$$

with $u_{w}, u_{c}$ and $v_{w}, v_{c}$ the cross-shelf and along-shelf RMS wave velocity and mean current velocities, respectively.

[35] This formulation is efficient to calculate large-scale coastal sediment transport. However, it requires priori knowledge on $C_{D}$ and $B$. On the basis of field data, $C_{D}$ is calibrated to be around 0.001-0.004 [Wright et al., 2001; Traykovski et al., 2007]. The buoyancy anomaly is estimated from the bulk Richardson number and total velocity [Wright et al., 2001]:

$$
B=\mathrm{Ri}_{\mathrm{B}} U^{2}
$$

[36] The bulk Richardson number of the fluid mud layer is often assumed to be 0.25 , i.e., the critical Richardson number with a marginally turbulent condition [e.g., Trowbridge and Kineke, 1994]. Essentially, the total amount of suspended mud, phrased as buoyancy anomaly, is considered as only a function of total velocity and an equilibrium assumption is utilized such that the total amount of suspended sediment exactly matches the carrying capacity of the turbulent flow. However, according to Case 1 and Case 2 discussed in section 3.1 and 3.2, the total amount of suspended sediment is not always related to RMS wave velocity but may be controlled by the availability of the unconsolidated mud. In addition, the critical Richardson number concept is mostly applicable to steady or tidal boundary layers. Recent laboratory experiments and field measurements suggest that the bulk Richardson number in the wave boundary layer is smaller than 0.25 [Lamb and Parsons, 2005; Traykovski et al., 2007]. Hence, it is necessary to further study the parameterization of buoyancy anomaly.

[37] In summary, there are several key questions related to the parameterization of wave-supported gravity-driven mudflows that can be studied using the present numerical model: (1) What is the magnitude of $C_{D}$ and its dependence on wave condition, the availability of mud and floc properties? (2) What is the magnitude of bulk Richardson number for wave-induced fluid mud layer and its dependence on wave condition, the availability of mud and floc properties?

[38] Detailed numerical model results allow us to evaluate the parameters used in the aforementioned 1D formulation. The RMS wave velocities and mean current velocities in the cross-shelf and along-shelf directions are directly evaluated from the time series measured at $75 \mathrm{cmab}$. The downslope gravity flow velocity $u_{g}$ is extracted from the model results based on the maximum velocity observed near the bed. The buoyancy anomaly is obtained by numerical integration of concentration across the water column according to equation (19). With all these physical quantities obtained from the numerical model results, $C_{D}$ and $\mathrm{Ri}_{\mathrm{B}}$ can be calculated using equations (17) and (21).

\subsection{Effects of Wave Intensity and Erodibility}

[39] The wave-supported gravity-driven mudflow studied here is different from the autosuspension turbidity current [Mulder and Syvitski, 1995; Imran and Syvitski, 2000]. The sediment-induced gravity current considered here must be supported by ambient waves or currents. Hence it is important to study the effects of wave intensity on fluid mud transport. As also discussed previously, the RMS wave velocities for moderate-concentration (Case 1) and highconcentration (Case 2) cases are similar. The major reason that is responsible for the observed large differences in fluid mud concentration appears to be erodibility. Using Case 1a shown in Figure 2 for moderate concentration and Case 2 shown in Figure 8 for high concentration, further numerical experiments are conducted by driving the model with several different intensities of wave velocity (see Tables 3 and 4 for details).

[40] For moderate-concentration condition (crosses in Figure 8a), the magnitude of drag coefficient decays as RMS wave velocity increases, which is qualitatively similar to the logarithmic formula used by Harris et al. [2004]. However, for high-concentration conditions (circles in Figure 8) with rheological stress incorporated, the resulting magnitude of drag coefficient is about 0.0013 and is more or less insensitive to the variations in wave intensity. Erodibility can change the degree of dependence of drag coefficients on wave intensity. For highly erodible mud, small waves

Table 3. Model Results for Different Magnitude of Wave Intensity for Moderate-Concentration Condition

\begin{tabular}{cccccc}
\hline $\begin{array}{c}\text { RMS Wave } \\
\text { Velocity }(\mathrm{m} / \mathrm{s})\end{array}$ & $\mathrm{U} \mid(\mathrm{m} / \mathrm{s})$ & $\mathrm{u}_{\mathrm{g}}(\mathrm{m} / \mathrm{s})$ & $\mathrm{B}\left(\mathrm{m}^{2} / \mathrm{s}^{2}\right)$ & $\mathrm{C}_{\mathrm{d}}$ & $\mathrm{Ri}_{\mathrm{B}}$ \\
\hline 0.26 & 0.281 & 0.014 & 0.0078 & 0.00397 & 0.09878 \\
0.39 & 0.404 & 0.056 & 0.0141 & 0.00124 & 0.08634 \\
0.52 & 0.531 & 0.084 & 0.0181 & 0.00081 & 0.06419 \\
0.65 & 0.662 & 0.114 & 0.019 & 0.00050 & 0.04336 \\
0.78 & 0.803 & 0.172 & 0.0166 & 0.00024 & 0.02574 \\
\hline
\end{tabular}


Table 4. Model Results for Different Magnitude of Wave Intensity for High-Concentration Condition

\begin{tabular}{cccccc}
\hline $\begin{array}{c}\text { RMS Wave } \\
\text { Velocity }(\mathrm{m} / \mathrm{s})\end{array}$ & $|\mathrm{U}|(\mathrm{m} / \mathrm{s})$ & $\mathrm{u}_{\mathrm{g}}(\mathrm{m} / \mathrm{s})$ & $\mathrm{B}\left(\mathrm{m}^{2} / \mathrm{s}^{2}\right)$ & $\mathrm{C}_{\mathrm{d}}$ & $\mathrm{Ri}_{\mathrm{B}}$ \\
\hline 0.255 & 0.272 & 0.080 & 0.0162 & 0.00149 & 0.21897 \\
0.383 & 0.392 & 0.082 & 0.0215 & 0.00134 & 0.14027 \\
0.510 & 0.520 & 0.090 & 0.0293 & 0.00125 & 0.10836 \\
0.638 & 0.644 & 0.087 & 0.0378 & 0.00135 & 0.09128 \\
0.765 & 0.771 & 0.097 & 0.0468 & 0.00125 & 0.07867 \\
\hline
\end{tabular}

can suspend a sufficient amount of mud to attenuate turbulence and cause noticeable drag reduction effect and hence maintain a lower value of drag coefficient. In contrast, during energetic wave conditions, high-concentration suspensions are formed. This causes large rheological stresses, which dominate the drag reduction effect and maintains (or even increases) the magnitude of drag coefficient. Similar effects on the reduction of variation of drag coefficient are obtained (not shown) when simulating moderate-concentration conditions with smaller fractal dimension and including rheological stresses (i.e., parameters used in Case 1c shown in Table 2). Hence, it is likely that when abundant mud is available, the counteracting effects between suppressed turbulence and rheological stress causes smaller variation of drag coefficient. Field data reported by Traykovski et al. [2007] for Po prodelta and Eel shelf suggests that the calculated drag coefficients of similar magnitude $(0.0012 \sim 0.0016)$ despite the larger wave intensity and greater fluid mud concentration measured at Eel shelf compared to the Po prodelta. This observation is consistent with the present modeling study.

[41] Model results also suggest that the bulk Richardson number for both moderate-concentration and highconcentration conditions is noticeably lower than 0.25 , the value of critical Richardson number. In addition, the bulk Richardson number is also not a constant. For moderateconcentration conditions (crosses in Figure 8b), it is reduced by about factor three as the wave intensity is increased by factor three. For high-concentration conditions, the bulk Richardson number is about 2-3 times larger than that of moderate-concentration conditions, especially for the case of lowest RMS wave intensity where the Bulk Richardson number exceeds 0.2 . Our analysis presented here is consistent with field data. Traykovski et al. [2007] summarize the sediment-induced gravity flow parameters measured during EuroSTRATAFORM and STRATAFORM [Traykovski et al., 2007, Table 2]. The bulk Richardson number calculated from measured total velocity and buoyancy anomaly suggests that during EuroSTRATAFORM, the bulk Richardson number ranges from 0.067 to 0.11 for R.M.S. wave velocity changing from $0.45 \mathrm{~m} / \mathrm{s}$ to $0.15 \mathrm{~m} / \mathrm{s}$. Moreover, during STRATAFORM where the measured mud concentration is larger (i.e., more available unconsolidated mud), the bulk Richardson is 0.16 for R.M.S. wave velocity around $0.6 \mathrm{~m} / \mathrm{s}$.

[42] Apparently, the justification of using critical Richardson number to estimate the buoyancy anomaly is based on abundant supply of cohesive sediment so that the total amount of suspended fine sediment is controlled by the carrying capability of the given flow forcing. In addition, the commonly accepted value of $\mathrm{Ri}_{\mathrm{B}}=0.25$ is also based on steady flow or tidal conditions. If the critical value of $\mathrm{Ri}_{\mathrm{B}}=$ 0.25 is also taken to be valid for wave boundary layer, our model results suggest that even in the high-concentration condition (Case 2a is the highest concentration measured during this field campaign), the supply of erodible fine sediments does not exceed the capability of the given wavecurrent forcing. It is possible that in most situations at the continental shelf, fine cohesive sediment transport is supply limited and the bulk Richardson number is smaller then its equilibrium value. Model results also suggest that when given more available sediment to the flow (through reducing critical stress or enhancing $\beta$ in equation (12)) and neglecting rheological stress, autosuspension may occur before the bulk Richardson number can reach an equilibrium value. Rheological stress can further enhance flow energy dissipation and mixing/suspension of sediment through enhanced sediment viscosity (see equation (15)), which can be another reason that the model results are not consistent with classical critical Richardson number concept.

[43] In reality, because of the uncertainties in floc properties (e.g., fractal dimension) and rheological properties, it is necessary to understand their effects on the sensitivity of the resulting gravity flow parameters. According to Case 1c (comparing to Case 1a), similar results can be obtained by using smaller fractal dimension and larger rheological stresses. Our numerical experiments based on Case 1c suggest that for low RMS wave condition, the suspended sediment concentration remains dilute and assuming a smaller fractal dimension gives smaller drag coefficient because of drag reduction. In contrast, large RMS wave conditions can support high-concentration suspensions and the drag coefficients can increase because of the effect of rheological stresses. In a qualitative sense, we can also make the following conjecture. If one were to assume completely deflocculated fine sediment with fractal dimension 3.0 (e.g., fine sediment diameter around few micrometers and density $2650 \mathrm{~kg} / \mathrm{m}^{3}$ ), such as that used by Wright et al. [2001], the calculated buoyancy anomaly and drag coefficient would become larger than what are calculated here. Larger buoyancy anomaly and drag coefficient are indeed reported by Wright et al. [2001] without explicitly considering the floc structure.

\section{Conclusion}

[44] Cohesive sediment transport is more difficult to model than noncohesive sediment transport in several aspects. In this study, we address these difficulties in terms of erodibility, floc properties (fractal dimension), and rheology. The erosion flux and critical stress for cohesive sediment are highly varying parameters that depend on the stage of consolidation and biological activities. In contrast, noncohesive coarser sand particles $(D>100 \mathrm{~m} \mu)$ settle much faster to form packed beds and the nondimensionalized critical bed stress (i.e., Shields parameter) is well accepted to be around 0.05 . Most existing cohesive sediment transport models must rely on in situ erodibility data. Through numerical model study and measured data during EuroSTRATAFORM on wave-supported gravity-driven mudflows and erodibility [Traykovski et al., 2007; Stevens et al., 2007], it is found that the detailed intrawave variation of critical stress is not crucial to the overall prediction of the time-averaged concentration and velocities (Figure 3). This 
is because the settling timescale (i.e., wave boundary layer thickness divided by settling velocity, which is around $10 \mathrm{~min}$ ) is in general much larger than intrawave period ( $\sim 10 \mathrm{~s})$. However, in situ information on near-bed concentration or averaged erodibility is still necessary to match the total amount of suspended fluid mud. The consolidation timescale (hours and days) is also much larger than the intrawave and settling timescales considered here, suggesting that a stand alone consolidation module [Sanford, 2008] may be incorporated in the cohesive sediment transport model to provide bulk averaged erodibility information. A more challenging situation that deserves more future study is when wave forcing is actively fluidizing the mud bed and increasing the erodibility.

[45] Unlike noncohesive sediments, cohesive sediment is transported as floc aggregates, which present additional unknowns in floc properties and the changes of floc size (floc dynamics) in the carrier flow [e.g., Winterwerp, 1998; Son and Hsu, 2008]. The basic mud floc properties are determined by the fractal dimension, which is qualitatively agreed upon to be around 2 but its specific value cannot be determined without in situ data. Model results suggest that when rheological stresses are not incorporated (or negligible), the predicted cross-shelf and along-shelf currents are sensitive to the prescribed fractal dimension. Smaller fractal dimension requires larger floc volume concentration to match the measured fluid mud mass concentration, which gives larger mean current velocity because of damped turbulence via drag reduction. The rheological closure for cohesive sediment is another highly empirical component. The role of rheological stress is to cause more friction (energy dissipation via interfloc interactions) in the boundary layer and hence incorporating larger rheological stresses reduces mean current. Our numerical study implies two scenarios that may occur in reality: For relatively low concentration fluid mud suspension $(\sim 10 \mathrm{~g} / \mathrm{L})$ with negligible rheological stresses, floc properties defined by the fractal dimension is the most important physical quantity that controls the dynamics of wave-supported gravitydriven mudflows. For high-concentration fluid mud suspensions $(\gg 10 \mathrm{~g} / \mathrm{L})$ with rheological stresses dominating turbulent Reynolds stress in the fluid mud layer, uncertainties in fractal dimension are of less importance, and the dynamics of fluid mud transport are controlled by the rheological closure. It is extremely desirable for the research community to further investigate floc properties and rheological stress during cohesive sediment transport through in situ measurements and more detailed modeling.

[46] Despite this study's focus on wave-supported gravitydriven mudflows, the numerical model developed here is based on general wave-current boundary layer formulation and is also able to model current-supported downslope gravity-driven mudflows. Through numerical experiment we demonstrate that the present model predicts currentdriven sediment-induced gravity flow characteristics that are consistent with recently observed field data at the mouth of Waiapu River, New Zealand [Ma et al., 2008].

[47] By analyzing the results of many numerical model experiments, gravity flow parameters used in the 1D parameterization [Wright et al., 2001] are discussed. When the availability of mud is abundant, the counteracting effects between attenuated turbulence and rheological stress allow a more or less constant value of drag coefficient for different wave intensity, consistent with prior field observations. The calculated bulk Richardson number is smaller than the critical Richardson number 0.25 , suggesting a supply limited condition for unconsolidated mud and/or a distinct difference between tidal and wave boundary layer processes. Moreover, the resulting bulk Richardson number and drag coefficient are also sensitive to prescribed floc properties and rheological stresses. In order to provide more accurate parameterization of wave-supported gravity-driven mudflows for large-scale coastal models, in situ erodibility and floc structure characterizations are critical.

[48] Acknowledgments. This study is supported by the Office of Naval Research grant N00014-09-1-0134 and grant N00014-06-1-0945 as part of the Community Sediment Transport Modeling System (CSTMS) through the National Oceanographic Partnership Program (NOPP). This study is also partially supported by National Science Foundation (OCE0644497).

\section{References}

Allen, J. R. L. (1985), Principles of Physical Sedimentology, Allen and Unwin, London.

Dadson, S., N. Hovius, S. Pegg, W. B. Dade, M. J. Horng, and H. Chen (2005), Hyperpycnal river flows from an active mountain belt, J. Geophys. Res., 110, F04016, doi:10.1029/2004JF000244.

Dalrymple, R. A., and P. L. Liu (1978), Waves over soft mud beds: A twolayer fluid mud model, J. Phys. Oceanogr., 8, 1121-1131, doi:10.1175 1520-0485(1978)008<1121:WOSMAT>2.0.CO;2.

Davies, A. G., R. L. Soulsby, and H. L. King (1988), A numerical model of the combined wave and current bottom boundary layer, J. Geophys. Res., 93, 491-508, doi:10.1029/JC093iC01p00491.

Dyer, K. R., and A. J. Manning (1999), Observation of the size, settling velocity and effective density of flocs, and their fractal dimensions, J. Sea Res., 41, 87-95, doi:10.1016/S1385-1101(98)00036-7.

Fan, S., D. J. P. Swift, P. A. Traykovski, S. J. Bentley, J. C. Borgeld, C. W. Reed, and A. W. Niedoroda (2004), River flooding, storm resuspension, and event stratigraphy on the northern California shelf: Observations compared with simulations, Mar. Geol., 210, 17-41, doi:10.1016/j. margeo.2004.05.024.

Ferry, J., and S. Balachandar (2001), A fast Eulerian method for disperse two-phase flow, Int. J. Multiphase Flow, 27, 1199-1226, doi:10.1016/ S0301-9322(00)00069-0.

Friedrichs, C. T., and L. D. Wright (2004), Gravity-driven sediment transport on the continental shelf: Implications for equilibrium profiles near river mouth, Coastal Eng., 51, 795-811, doi:10.1016/j.coastaleng. 2004.07.010.

Geyer, W. R., P. Hill, T. Milligan, and P. Traykovski (2000), The structure of the Eel River plume during floods, Cont. Shelf Res., 20, 2067-2093, doi:10.1016/S0278-4343(00)00063-7.

Gust, G. (1976), Observations on turbulent-drag reduction in a dilute suspension of clay in sea-water, J. Fluid Mech., 75, 29-47, doi:10.1017/ S0022112076000116.

Harris, C. K., P. A. Traykovski, and R. W. Geyer (2004), Including a nearbed turbid layer in a three-dimensional sediment transport model with application to the Eel River shelf, northern California, in Proceedings of the Eighth Conference on Estuarine and Coastal Modeling, edited by M. Spaulding, pp. 784-803, Am. Soc. of Civ. Eng., Reston, Va.

Harris, C. K., P. A. Traykovski, and W. R. Geyer (2005), Flood dispersal and deposition by near-bed gravitational sediment flows and oceanographic transport: A numerical modeling study of the Eel River shelf, northern California, J. Geophys. Res., 110, C09025, doi:10.1029/ 2004JC002727.

Hsu, T.-J., P. A. Traykovski, and G. C. Kineke (2007), On modeling boundary layer and gravity-driven fluid mud transport, J. Geophys. Res., 112, C04011, doi:10.1029/2006JC003719.

Huang, X., and M. H. Garcia (1999), Modeling of non-hydroplaning mudflows on continental slopes, Mar. Geol., 154, 131-142, doi:10.1016/ S0025-3227(98)00108-X.

Imran, J., and J. P. M. Syvitski (2000), Impact of extreme river events on the coastal ocean, Oceanography, 13, 85-92.

Kranenburg, C. (1994), The fractal structure of cohesive sediment aggregates, Estuarine Coastal Shelf Sci., 39, 451-460.

Lamb, M. P., and J. D. Parsons (2005), High-density suspensions formed under waves, J. Sediment. Res., 75, 386-397, doi:10.2110/jsr.2005.030 
Le Hir, P., P. Bassoulet, and H. Jestin (2001), Application of the continuous modeling concept to simulate high-concentration suspended sediment in a macro-tidal estuary, in Coastal and Estuarine Fine Sediment Processes, Proc. Mar. Sci., vol. 3, edited by W. H. McAnally and A. J. Metha, pp. 229-248, Elsevier Sci., Amsterdam.

Lesser, G. R., J. A. Roelvink, A. T. M. J.van Kester, and G. S. Stelling (2004), Development of a three-dimensional morphological model, Coastal Eng., 51, 883-915, doi:10.1016/j.coastaleng.2004.07.014

Ma, Y., D. L. Wright, and C. F. Friedrichs (2008), Observation of sediment transport on the continental shelf off the mouth of the Waiapu River, New Zealand: Evidence for current-supported gravity flows, Cont. Shelf Res., 28, 516-532, doi:10.1016/j.csr.2007.11.001.

Maa, P.-Y., and A. J. Mehta (1987), Mud erosion by waves: A laboratory study, Cont. Shelf Res., 7, 1269-1284.

Mei, C. C., and K. F. Liu (1987), A Bingham plastic model for a muddy seabed under long waves, J. Geophys. Res., 92, 14,581-14,594, doi:10.1029/JC092iC13p14581.

Milliman, J. D., and S. J. Kao (2005), Hyperpycnal discharge of fluvial sediment to the ocean: Impact of Super-Typhoon Herb (1996) on Taiwanese rivers, J. Geol., 113, 503-506, doi:10.1086/431906.

Milliman, J. D., and J. P. M. Syvitski (1992), Geomorphic/tectonic control of sediment discharge to the ocean: The importance of small mountain rivers, J. Geol., 100, 525-544.

Milliman, J. D., S. W. Lin, S. J. Kao, J. P. Liu, C. S. Liu, J. K. Chiu, and Y. C. Lin (2007), Short-term changes in seafloor character due to floodderived hyperpycnal discharge: Typhoon Mindulle, Taiwan, July 2004 Geology, 35, 779-782, doi:10.1130/G23760A.1.

Mulder, T., and J. P. M. Syvitski (1995), Turbidity currents generated at river mouths during exceptional discharges to the world oceans, J. Geol., $103,285-299$.

Nittrouer, C. A., and J. H. Kravitz (1996), STRATAFORM: A program to study the creation and interpretation of sedimentary strata on continental margins, Oceanography, 9, 146-152.

Nott, P. R., and J. F. Brady (1994), Pressure-driven flow of suspension: Simulation and theory, J. Fluid Mech., 275, 157-199, doi:10.1017/ S0022112094002326.

Ogston, A. S., D. A. Cacchione, R. W. Sternberg, and C. G. Kineke (2000), Observation of storm and river flood-driven sediment transport on the northern California continental shelf, Cont. Shelf Res., 20, 2141-2162, doi:10.1016/S0278-4343(00)00065-0.

Parker, G. (1982), Condition for the ignition of catastrophically erosive turbidity currents, Mar. Geol., 46, 307-327, doi:10.1016/00253227(82)90086-X.

Richardson, J. F., and W. N. Zaki (1954), Sedimentation and fluidization, part 1, Trans. Inst. Chem. Eng., 32, 35-53.

Sanford, L. P. (2008), Modeling a dynamically varying mixed sediment bed with erosion, deposition, bioturbation, consolidation, and armoring, Comput. Geosci., 34, 1263-1283, doi:10.1016/j.cageo.2008.02.011.

Sanford, L. P., and J. P. Halka (1993), Assessing the paradigm of mutually exclusive erosion and deposition of mud, with examples from upper Chesapeake Bay, Mar. Geol., 114, 37-57, doi:10.1016/00253227(93)90038-W.

Sanford, L. P., and J. P.-Y. Maa (2001), A unified erosion formulation for fine sediments, Mar. Geol., 179, 9-23, doi:10.1016/S0025-3227 (01)00201-8.

Scully, M. E., C. T. Friedrichs, and L. D. Wright (2002), Application of an analytical model of critically stratified gravity-driven sediment transport and deposition to observations from the Eel River continental shelf, northern California, Cont. Shelf Res., 22, 1951-1974, doi:10.1016/ S0278-4343(02)00047-X.

Sherwood, C. R., et al. (2004), Sediment dynamics in the Adriatic Sea investigated with coupled models, Oceanography, 17, 58-69.

Son, M., and T.-J. Hsu (2008), Flocculation model of cohesive sediment using variable fractal dimension, Environ. Fluid Mech., 8, 55-71, doi:10.1007/s10652-007-9050-7.

Stevens, A. W., R. A. Wheatcroft, and P. L. Wiberg (2007), Seabed properties and sediment erodibility along the western Adriatic margin, Italy, Cont. Shelf Res., 27, 400-416, doi:10.1016/j.csr.2005.09.009.
Syvitski, J. P. M., J. N. Smith, E. A. Calabrese, and B. P. Boudreau (1988), Basin sedimentation and the growth of prograding deltas, J. Geophys. Res., 93, 6895-6908, doi:10.1029/JC093iC06p06895.

Traykovski, P., W. R. Geyer, J. D. Irish, and J. F. Lynch (2000), The role of wave-induced fluid mud flows for cross-shelf transport on the Eel River continental shelf, Cont. Shelf Res., 20, 2113-2140, doi:10.1016/S02784343(00)00071-6.

Traykovski, P., P. Wiberg, and W. R. Geyer (2007), Observations and modeling of wave-supported sediment gravity flows on the Po prodelta and comparison to prior observations from the Eel shelf, Cont. Shelf Res., 27, 375-399, doi:10.1016/j.csr.2005.07.008.

Trowbridge, J. H., and G. C. Kineke (1994), Structure and dynamics of fluid mud on the Amazon continental shelf, J. Geophys. Res., 99, 865874, doi:10.1029/93JC02860.

van der Ham, R., and J. C. Winterwerp (2001), Turbulent exchange of fine sediments in a tidal channel in the Ems/Dollard estuary. Part I: Analysis with a 1DV numerical model, Cont. Shelf Res., 21, 1629-1647, doi:10.1016/S0278-4343(01)00011-5.

Vinzon, S. B., and A. J. Mehta (1998), Mechanism for formation of lutoclines by waves, J. Waterw. Port Coastal Ocean Eng., 124, 147-149, doi:10.1061/(ASCE)0733-950X(1998)124:3(147).

Warner, J. C., C. R. Sherwood, R. P. Signell, C. K. Harris, and H. G. Arango (2008), Development of a three-dimensional, regional, coupled wave, current and sediment-transport model, Comput. Geosci., 34, 1284-1306, doi:10.1016/j.cageo.2008.02.012.

Wheatcroft, R. A. (2000), Oceanic flood sedimentation: A new perspective, Cont. Shelf Res., 20, 2059-2066, doi:10.1016/S0278-4343(00)00062-5.

Wheatcroft, R. A., and J. C. Borgeld (2000), Oceanic flood deposits on the northern California shelf: Large-scale distribution and small-scale physical properties, Cont. Shelf Res., 20, 2163-2190, doi:10.1016/S02784343(00)00066-2.

Wiberg, P. L., D. E. Drake, and D. A. Cacchione (1994), Sediment resuspension and bed armoring during high bottom stress events on the northern California continental shelf: Measurements and predictions, Cont. Shelf Res., 14, 1191-1219, doi:10.1016/0278-4343(94)90034-5.

Winterwerp, J. C. (1998), A simple model for turbulence induced flocculation of cohesive sediment, J. Hydraul. Res., 36, 309-326.

Winterwerp, J. C., and W. G. M. van Kesteren (2004), Introduction to the Physics of Cohesive Sediment in the Marine Environment, Elsevier, New York.

Wolanski, E., J. Chappell, P. Ridd, and R. Vertessy (1988), Fluidization of mud in estuaries, J. Geophys. Res., 93, 2351-2361, doi:10.1029/ JC093iC03p02351.

Wright, L. D., and J. M. Coleman (1972), River delta morphology: Wave climate and role of subaqueous profile, Science, 176, 282-283, doi:10.1126/science.176.4032.282.

Wright, L. D., and C. T. Friedrichs (2006), Gravity-driven sediment transport on continental shelves: A status report, Cont. Shelf Res., 26, $2092-$ 2107.

Wright, L. D., and C. A. Nittrouer (1995), Dispersal of river sediments in coastal seas: Six contrasting cases, Estuaries, 18, 494-508, doi:10.2307/ 1352367.

Wright, L. D., C. T. Friedrichs, S. C. Kim, and M. E. Scully (2001), Effects of ambient currents and waves on gravity-driven sediment transport on continental shelves, Mar. Geol., 175, 25-45, doi:10.1016/S00253227(01)00140-2.

T.-J. Hsu, Center for Applied Coastal Research, Civil and Environmental Engineering, University of Delaware, Newark, DE 19716, USA. (thsu@ udel.edu)

C. E. Ozdemir, Civil and Coastal Engineering, University of Florida, Gainesville, FL 32611, USA.

P. A. Traykovski, Applied Ocean Physics and Engineering, Woods Hole Oceanographic Institution, Woods Hole, MA 02543, USA. 